\title{
Mimicking Media: Funny Means To Achieve Serious End
}

\author{
${ }^{1,}$ Dr. Mubasher Nadeem, ${ }^{2,}$ Salman Akram, ${ }^{3,}$ Anzar Mehmaan \\ ${ }^{1,}$ Director, Division of Arts \& Social Sciences, University of Education Lahore.

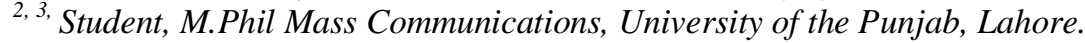

\begin{abstract}
Although a literary term used primarily to ridicule somebody or some issue Satire has been used very effectively by the satirical media in Pakistan through various late night T.V talk shows. This article examines the role being played by T.V talk shows amalgamated with satire, irony or caricature to either develop the perception of the people or get them familiarized with on going socio-political, socio-economic and educational issues/happenings in Pakistan. The qualitative study was conducted, through focused group interview, on 100 University students. The subjects apparently appear to be appropriate sample because they represent a majority that remains unmoved because of monotony in various talk shows but is capable of steering socio-economic, educational and democracy boat in the right direction if attracted properly to un-talked issues in the country. In the light of the findings of the study it is concluded that such monotony takes the general masses, especially youth, away from ongoing debatable issues of Pakistan but the mimicking media has brought the same general masses and youth back to feel concerned about such issues to form their opinions. Further, the subjects suggest that free media in Pakistan is at growing stage and socio-economic, socio-political or educational, etc., issues may not be discussed bitterly but in a light tone and manner to educate people rather to irritate. Hence, mimicking media could be a very positive effort by T.V channels to educate people of Pakistan where much is to be done in social sector so that they may contribute effectively to make Pakistan socially, economically, educationally and politically a stable and progressive country.
\end{abstract}

Key Words: Mimicking media, satire, irony, caricature, socio-economic, socio-political, educational, light tone

\section{Premise}

"The 'hypodermic needle theory'(Lasswell, 1927) that the radio and television were thought to have direct and immediate impact on their audiences, with messages shot directly to the brain like a hypodermic needle" has remained the focus of many media men regarding the impact of radio and television on the message receivers. And in the famous words of McCombs and Shaw, "the mass media may not be successful in telling us what to think, but they are stunningly successful in telling us what to think about" (McCombs \& Shaw, 1972).

\section{Background}

During the recent past media in Pakistan has experienced revolutionary changes despite having seen many ups and downs as well as various types of censorships imposed both by dictatorial and democratic rulers. The presence of approximately $83 \mathrm{~T} . \mathrm{V}$ channels in Pakistan has itself become another challenge for the owners on one hand and for the viewers and the rulers on the other. There are some channels which have surely made progress by leaps and bounds where as the others may be in evolutionary stage.

Factually speaking, today's media has rather got the rulers out of lethargy and tolls a new bell for them to set their direction on right track. But there is no denying the fact that talk shows, which are primarily focused on politics or politics related issues, have taken a majority of viewers, especially the youth, away from not only media but to the world of politics which is the ultimate way to get the right people to steer the boat of nourishing democracy in Pakistan. But among all the genres (Matsa, 2010) the most contemporary and influential seems to be comedic satirical shows on television and its influence appears closely related to the special characteristics of the medium (i.e. the TV). Recent literature has shown that comedy shows hold a special relationship with their audience and that they have significant impact on viewers' political perceptions, political engagement and knowledge about public affairs (Baumgartner \& Morris: 2006; Cao \& Brewer: 2008; Pew Research Center's Project for Excellence in Journalism: 2008).

Media in Pakistan probably have checked the pulse of viewers as many news channels have started using satire or irony to attract the viewers as well as to get them aware about the political, social, economic, religious, and educational, ete., issues which are directly associated with them and affecting the dimensions of their life. A new form of media, light in tone but grave in deeper sense, is taking place in Pakistan which seems not to offend those who are to choose a socio-economically progressive stable path so that an under trodden nation may get out of the vicious circle of 'International Antagonism' towards Pakistan because of the sin never committed by the Pakistanis. In other words Pakistan has become a country more sinned against than sinning. 
The burgeoning "new media" has been best defined by Richard Davis and Diana Owen as, "mass communication forms with primarily nonpolitical origins that have acquired political roles" (Davis \& Owen, 1998).

\section{Rationale, study question and design}

"The 'hypodermic needle theory'(Lasswell, 1927) that the radio and television were thought to have direct and immediate impact on their audiences, with messages shot directly to the brain like a hypodermic needle" has remained the focus of many media men regarding the impact of radio and television on the message receivers. And in the famous words of McCombs and Shaw, "the mass media may not be successful in telling us what to think, but they are stunningly successful in telling us what to think about" (McCombs \& Shaw 1972).

Hence, this study aims to investigate the importance of mimicking media in the present socio-political or socio-economic and educational context that to what extent it is serving the purpose of training people of Pakistan, especially youth, about various issues which Pakistan is facing presently as well as to find out whether or not it is successful in presenting socio-economic, educational or political issues to the people of Pakistan with an aim to offer them open ended choice to decide what's right and what's wrong in a light tone but deeper in effect so that people may take the right decision for the progress of this country.

Keeping in view its primary aim this qualitative study has been conducted on one hundred university graduates studying in different degree programmes. A focused group interview (appendix A) was conducted by keeping in view the objectives, content, purpose and effects of various T.V talk shows containing mimicry as a tool to serve their objective.

\section{Review of Literature}

The word satire has taken on many forms in modern-day culture. Originally used as tool to mock or deride the natural failings of human nature, satire is currently used interchangeably with comedy, parody or even humor to describe and lampoon events that

make us laugh. When it comes to satire on television, 'The Daily Show' is often described by many as a comedy or satirical television show (Gray, et al., 2009).

In USA for decades now, the youngest segment of the American public has been losing interest in the news. Surveys of media usage for people ages 18 to 29 show they consume traditional news media—newspapers and network news programs - at much lower rates then either their parents or grandparents (Pew Research Center 2000, Pew Research Center 2004). This has led (Larris, 2005) to concerns voiced by political scholars and politicians alike as to where this segment of society is getting their news and where they will get their news when they are older. The youngest generation's general disinterest in political news from an early age lends itself to the belief that this is the cause for decreasing levels of voting across generations because, as the youngest age, they do not gain an interest in news or politics (Patterson, 2002).

As (Postman, 1986), while commenting on American media, says that unlike some cultural critics who wish to divide political discourse into serious and frivolous categories Jones views this development as an expansion of the political realm but one which allows other voices beyond the so-called experts to engage in political talk in a language that is common to average Americans. Comedian-hosts with a different license to speak offer political critiques beyond the scope of what news and pundit political talk have previously imagined (Jones, 2005). In such T.V shows serious hosts whose job may be to raise any issue for comic responses with the help of either some comedians or caricature of some known personalities particularly from the arena of politics. And by creating ambiguous comic remarks, gestures, responses, of his/her associate/s the hosts tend to achieve the objective of getting the audience generates a sense of awareness related to socio-political issues of the country.

In recent years (LaMarre, et al., 2009) there has been a surge of political entertainment studies within mass communication. These studies have demonstrated a series of effects of political entertainment on individual-level socio-political attitudes related to a variety of political issues (Holbert et al., 2003; Holbert et al., 2004), as well as a strong set of relationships between late-night comedy and individual-level political attitudes and behaviors (Young \& Tisinger, 2006). Late-night comedy studies have demonstrated significant effects ranging from primacy and recency (Holbert et al. 2007) to acquisition of political knowledge (Young, 2008). Such findings are consistent with political entertainment research, which demonstrate the influence of prime-time television on individual-level political perceptions, attitudes, opinions, and behaviors (Delli Carpini \& Williams, 1994; Holbrook \& Hill, 2005).

Ambiguous satire, pertaining to political and social issues, catches the attention of the viewers because its primary purpose appears to get the audience become conscious about the state of affairs in the concerned areas and it is done effectively especially in the late night T.V programmes on different channels of Pakistan. Late-night comedy studies have demonstrated significant effects ranging from primacy and recency (Holbert et al., 2007) to acquisition of political knowledge (Young, 2008). Such findings are consistent with political 
entertainment research, which demonstrate the influence of prime-time television on individual-level political perceptions, attitudes, opinions, and behaviors (Delli Carpini \& Williams, 1994; Holbrook \& Hill, 2005).

The unbiased effort made through such T.V programmes serves people's general demand of getting information but in an impartial way. Recent work in social psychology demonstrates that individuals process information in ways that personally benefit them and that people tend to see what they want to see when the information is ambiguous (Balcetis \& Dunning 2006; Kunda 1990; Long \& Toppino 2004). Conversely, other media genres of a more informative character are adopting important elements from entertainment (Hjarvard 1999, McManus 1994) in order to attract and secure their audiences.

Since the early 1990s the TV satire genre has experienced an intensive development. In close interplay with the Internet the genre has become a means in an increasingly focused target group orientation undertaken by Danish public service TV entertainment (Bruun 2005a). However, TV satire is not a new venture. The genre has formed part of Danish TV entertainment since 1968 when it spearheaded an attempt by public service TV to offer entertainment of broad appeal, but with a critical, evaluative gambit for political and socio-cultural selfreflection (Bruun 2005b, Hutcheon 1985, Larsen 2001).

Further, the youngest generation's general disinterest in political news from an early age lends itself to the belief that this is the cause for decreasing levels of voting across generations because, as the youngest age, they do not gain an interest in news or politics (Patterson, 2002). This disinterest (Larris, 2005) creates patterns of non-traditional news followers who do not watch the nightly news and do not read newspapers. To many, this is a cause for concern. A view of democracy, dating back to the Progressive era, cites that the cornerstone of American democracy presupposes that there is an informed citizenry. Even our country's founding forefathers waxed eloquent about the role of newspapers, i.e. news, in their society. An uninformed citizen is one who cannot guide the actions of their government. In any case those who do not follow the news regularly are far less likely to vote (Patterson, 2002).

On the other hand traditionally, comedians have long denied that their jokes or words have any impact on their audience's political viewpoints, essentially denying that they are opinion-leaders. Jay Leno,host of The Tonight Show asserts, "You don't change everybody's mind. You just reinforce what people already believe" (Levin 2000). For his part, Jon Stewart often denies any impact his show may have on either the presidential race or on votes, stating time and again that his program is "fake news."

I don't think it's possible [for young people to get much of their news from The Daily Show]. We're on Channel 45-in New York! Literally on the remote- control journey you could absorb more news than you would get from our show... Our politics are fueled by comedy. We're not a power base in any way. Our show is so reactionary, it's hard to imagine us stimulating the debate (Peyser, 2003).

But the more powers of influence the popular press (Sella, 2000) wishes to confer to comedians the more strenuously comedians deny any links between their program's and their audience's viewpoints (Davis \& Owen, 1998).

\section{Findings And Conclusion}

This qualitative study was designed to know the reflections of youth of Pakistan about the role of newly emerged media, i.e., mimicking media, in Pakistan in respect of its contribution in the making of opinion of the youth about socio-economic, socio-political and educational, etc., issue in the country after considering the present state of affairs in Pakistan. The focused group based study provided the researcher/s new dimensions furnished by the respondents when a majority has favoured the new type of media.

The results show that a vast majority of the respondents was getting away soon after the experiencing the daily hard and cross talks on various T.V programs and lost interest in watching T.V, which ultimately led them find other means of information as well as entertainment on T.V channels. But as the opinions of the subjects reflect that the new kind of media has caught their attention when T.V talks shows, having lighter tone for serious issues, present hard, bitter and crude realities in a light tone to leave deeper impact on the viewers. It is blessing in disguise that Pakistan's majority comprises of youth which is getting maturity about serious issues affecting society of this country.

Some of the important remarks of the respondents have been recorded below:

"I never expected that our media has such potentials especially by channelizing the talent of stage artists who are normally taken as entertainers only but by the efforts of different anchors they have started teaching people what to think about on various issues".

\section{Another respondent said: \\ "T.V channels have done a great job especially some anchors who have dared coining such programs to bring back viewers close to T.V sets so that people may know right and wrong to make their opinion".}




\section{One respondent uttered the following remark:}

"I heard that stage dramas are nothing but piece of vulgarity. Now I think otherwise because people of meager educational qualification have proved, with the help of T.V anchors, how re-direct the opinion of the people of Pakistan especially youth".

\section{One respondent said:}

"I wonder how beautifully and tactfully such T.V talk shows are getting the people out of stress in these circumstances when we don't know who is right and who is wrong".

\section{A respondent felt that:}

"I feel it's great achievement to have such light T.V talk shows because highly serious issues are talked in very light tone but that surely leaves a lot to think further...".

\section{And one more stated his opinion like this:}

"I never find a good T.V viewer in me but after having seen such T.V talk shows I am becoming a couch potato so far as these light T.V talk shows are concerned".

\section{One respondent said:}

"Such T.V talk shows are not comedy programs but are piercing arrows for those who want this nation to become a nation".

\section{One respondent commented:}

"At least, now I have decided to cast my vote for a better Pakistan".

\section{One respondent said:}

"All work and no play make Jack a dull boy. So these talk shows are providing a sense of comfort to us on one side and educating us on the other".

Keeping in view the results of the study the researchers are in the position to say that the newly emerged media is shouldering its responsibility and despite all odds has endeavored to catch the attention of the people, especially youth, as some of the subjects opined that their families are very much interested to watch such T.V talk shows on the logic that these programs are double egged sword; they entertain and educate.

It is important to mention that most of the Pakistanis appear to be aloof from ongoing socio-economic, socio-political and educational issues which are hardly discussed at educational institutions for opinion making but such T.V talk shows have started education people by adopting a funny path to achieve serious end. There may be critics of this effort but in the light of the findings of the study it may be assumed that as a sister branch of serious media this could be accommodated, if such T.V talk shows are rendering the purpose they aim at which is to familiarize the people, especially youth, with the actual state of affairs in various socio-economic, socio-political and educational arenas of Pakistan.

Hence, the study suggests that this newly emerged media may be considered equal with already prevalent genres of existing media for better Pakistan and Pakistanis and 'hypodermic needle theory' is very much applicable to the newly emerged media in Pakistan. Further, the opinion of (McCombs \& Shaw 1972) that the mass media may not be successful in telling us what to think, but they are stunningly successful in telling us what to think about, is apt when attached with mimicking media in Pakistan.

\section{References}

[1] Balcetis, Emily, and David Dunning. 2006. "See What You Want to See: Motivational Influences on Visual Perception." Journal of Personality and Social Psychology 91(4):612-25.

[2] Baumgartner, J. \& Morris, J.S. 2006, 'The Daily Show Effect: Candidate Evaluations,

[3] Efficacy, and American Youth', American Politics Research, vol. 34, no. 3, pp. 341-367.

[4] Bruun, H. (2005a) 'Public Service and Entertainment', in Ferrell Lowe, Gregory and Jauert, Per (eds.) Cultural Dilemmas in Public Service Broadcasting. Göteborg: Nordicom.

[5] Bruun, H. (2005b) 'Tv-underholdning', in Stig Hjarvard (red.) Dansk tv-historie 1951-2001. Frederiksberg: Samfundslitteratur.

[6] Richard, D., \& Owen, D. (1998). New Media and American Politics. New York:

[7] Oxford University Press.

[8] Delli Carpini, Michael X., and Bruce A. Williams. 1994. "Methods, Metaphors, and Media Research: The Uses of Television in Political Conversation." Communication Research 21(6):782-812.

[9] Gray, J., Jones, J.P. \& Thompson, E. (2009). Satire TV: Politics and Comedy in the Post-

[10] Network Era, NYU Press, New York.

[11] Kunda, Ziva. 1990. "The Case for Motivated Reasoning." Psychological Bulletin 108(3):480-98.

[12] Hjarvard, Stig (1999) TV-Nyheder i konkurrence. København: Samfundslitteratur.

[13] Holbert, R. Lance, Jennifer L. Lambe, Anthony D. Dudo, and Kristin A. Carlton. 2007. "Primacy Effects of the Daily Show and National TV News Viewing: Young Viewers, Political Gratifications, and Internal Political Self-Efficacy.” Journal of Broadcasting \& Electronic Media 51(1):20-38. 
[14] Holbert, R. Lance, Dhavan V. Shah, and Nojin Kwak. 2003. "Political Implications of Prime-Time Drama and Sitcom Use: Genres of Representation and Opinions Concerning Women's Rights." Journal of Communication 53(1):45-60.

[15] Holbert, R. Lance, Dhavan V. Shah, and Nojin Kwak. 2004. "Fear, Authority, and Justice: The Influence of TV News, Police Reality, and Crime Drama Viewing on Endorsements of Capital Punishment and Gun Ownership." Journalism \& Mass Communication Quarterly 81(2):343-63.

[16] Holbrook, R. Andrew, and Timothy Hill. 2005. "Agenda-Setting and Priming in Prime Time Television: Crime Dramas as Political Cues.” Political Communication 22(3):277-95.

[17] Hutcheon, L. (1985). A Theory of Parody. London: Routledge.

[18] Jones, J. P. (2005). Entertaining Politics. Lanham, Maryland: Rowman \& Littlefield

[19] Publishers.

[20] Katerina-Eva Matsa, (2010). Laughing at Politics: Effects of Television Satire on Political Engagement in Greece. A Thesis submitted to the Faculty of the Graduate School of Arts and Sciences of Georgetown University in partial fulfillment of the requirements for the degree of Master of Arts in Communication, Culture and Technology. Washington, DC.

[21] Larsen, J. (2001) 'Tourism Mobilities and The travel Glance: Experiences of being on the Move', Scandinavian Journal of Hospitality and Tourism, Vol. 1, No. 2.

[22] Lasswell, H.D. (1927). Propaganda Technique in the World War. New York: Knopf.

[23] Levin, G. 2000. Bush, Gore work late shift for laughs; Humor may help sway young

[24] voters. USA Today. October 23, 4D.

[25] Long, George, and Thomas Toppino. 2004, "Enduring Interest in Perceptual Ambiguity: Alternating Views of Reversible Figures. Psychological Bulletin 13:748-68.

[26] McManus, J. H. (1994). Marketdriven Journalism. Sage.

[27] McCombs, M.E., \& Shaw, D.L.. 1972. The agenda setting function of mass media. Public Opinion Quarterly, 36(1), 176-187.

[28] Neil, P. (1986). Amusing Ourselves to Death: Public Discourse in the Age of Show Business. New York: Penguin Books.

[29] Patterson, T. (2002). The Vanishing Voter. New York: Vintage Books.

[30] Pew Research Center for the People and the Press, 2008, 'Who Knows News? What You

[31] Read or View Matters, but Not Your Politics' [Online] Available at:

[32] http://pewresearch.org/pubs/993/who-knows-newswhat-you-read-or-view-matters-butnot-your-politics. Retrieved March, 13, 2012.

[33] Pew Research Center for People and The Press. 2004. Perceptions of partisan bias seen

[34] as growing - Especially by Democrats. January 11, 2004. Washington, DC.

[35] 2000. Audiences fragmented and skeptical: The tough job of communicating with voters.

[36] Peyser, Marc. Dec. 29, 2003/Jan. 5. 2004. Red, white \& funny. Newsweek. 71.

[37] Rachel Joy Larris. The Daily Show Effect: Humor, News, Knowledge and Viewers. Washington, D.C. May 2, 2005.

[38] Sella, Marshall. 2000. The Stiff guy vs. the dumb guy. New York Times. September

[39] 24.

[40] The Daily Show Effect: Humor, News, Knowledge and Viewers A Thesis Submitted to the Faculty of the Graduate School of Arts and Sciences of Georgetown University in partial fulfillment of the requirements for the degree of Master of Arts in Communication, Culture, and Technology By Rachel Joy Larris, B.A. Washington, D.C. May 2, 2005.

[41] Thomas, P. (2002). The Vanishing Voter. New York: Vintage Books.

[42] Young, Dannagal G., \& Russell M. Tisinger. (2006). "Dispelling Late-Night Myths: News Consumption among Late-Night Comedy Viewers and the Predictors of Exposure to Various Late-Night Shows." Harvard International Journal of Press/Politics 11(3):113-34.

[43] Young, Dannagal G. (2008). “The Privileged Role of the Late-Night Joke: Exploring Humor's Role in Disrupting Argument Scrutiny.” Media Psychology 11(1):119-42.

\section{Appendix A}

\section{Focus Group Interview Male and Female}

Q: What you think are the main problems of electronic media that hinder it to improve perception of the people of Pakistan, especially youth, in respect of their understanding of socio-political or socio-economic and educational issues? Important remark/s of the respondent/s

Q: Why do a majority of the young people seem to get away from media and talk shows containing matter that only brings some political party workers accuse each other?

Important remark/s of the respondent/s

Q: How important is the role of today's media in educating people, especially youth, in forming their opinion about the on going socio-political or socio-economic and educational issues as well as future of democracy in Pakistan?

Important remark/s of the respondent/s

Q: What do feel you about the newness in media that may be called mimicking media? Important remark/s of the respondent/s

Q: How do you see the role of such T.V talk shows presenting serious issue in a light tone to generate deeper sense of understanding?

Important remark/s of the respondent/s

Q: I am interested to know your opinion about other possible contribution/s of such T.V talk shows in the present sociopolitical or socio-economic and educational scenario of Pakistan.

Important remark/s of the respondent/s 